\title{
ClariCore Optical Biopsy System
}

National Cancer Institute

\section{Source}

National Cancer Institute. ClariCore Optical Biopsy System. NCI Thesaurus. Code C153338.

A proprietary system for prostate cancer biopsy collection. The system uses an optical fiber "needle", spectral analysis, and a proprietary algorithm to disting uish normal tissue from suspicious tissue. It then guides the collection of biopsy samples when suspicious tissue is identified. 